\title{
Vitrectomy for optic disc pit-associated maculopathy with or without preoperative posterior vitreous detachment
}

This article was published in the following Dove Press journal:

Clinical Ophthalmology

22 August 2012

Number of times this article has been viewed

\section{Masatoshi Haruta \\ Rika Kamada \\ Yumi Umeno \\ Ryoji Yamakawa}

Department of Ophthalmology, Kurume University School of Medicine, Kurume, Fukuoka, Japan
Correspondence: Masatoshi Haruta Department of Ophthalmology, Kurume University School of Medicine, 67 Asahi-machi, Kurume, Fukuoka, 830-00 II, Japan

$\mathrm{Tel}+8$ I 9423 3। 7574

Fax +8I 942370324

Email haruta_masatoshi@med.kurume-u. ac.jp
Background: The purpose of this study was to evaluate the efficacy of pars plana vitrectomy for the treatment of optic disc pit-associated maculopathy with or without preoperative posterior vitreous detachment.

Methods: We reviewed the clinical records of four consecutive patients who underwent pars plana vitrectomy in one eye for the treatment of optic disc pit-associated maculopathy, with an emphasis on the preoperative condition of the posterior hyaloid membrane.

Results: Two of four eyes were confirmed to have an attached posterior hyaloid membrane, which was subsequently removed during surgery. Following vitrectomy, these two eyes experienced an improvement in visual acuity with complete retinal attachment of the macula. However, the other two eyes, which already had a posterior vitreous detachment at the time of surgery, showed a decrease in visual acuity with persistent maculopathy postoperatively.

Conclusion: Pars plana vitrectomy for optic disc pit-associated maculopathy was beneficial for improving visual acuity in two eyes without preoperative posterior vitreous detachment but not in two eyes with preoperative posterior vitreous detachment. Our study suggests that preoperative assessment of a posterior hyaloid membrane is clinically important in predicting the surgical outcome of optic disc pit-associated maculopathy.

Keywords: gas tamponade, internal limiting membrane, macular hole, optical coherence tomography, posterior hyaloid membrane, retinal detachment

\section{Introduction}

An optic disc pit is a rare congenital anomaly that may develop macular fluid accumulation within or under the neural retina. We reviewed the clinical records of four consecutive patients who underwent pars plana vitrectomy in one eye for the treatment of optic disc pit-associated maculopathy, with an emphasis on the preoperative condition of the posterior hyaloid membrane.

\section{Case report I}

A 50-year-old male with left optic disc pit-associated maculopathy and best-corrected visual acuity of 0.2 OS underwent combined phacoemulsification with intraocular lens implantation and 20-gauge pars plana vitrectomy. Preoperative slit-lamp examination showed a mobile prepapillary glial ring in the left eye. Preoperative assessment of posterior vitreous detachment (PVD) was confirmed intraoperatively by using a silicone-tipped extrusion needle. Fluid-air exchange was performed, followed by gas tamponade with sulfur hexafluoride and postoperative facedown positioning for approximately one week. Two months after the vitrectomy, the patient was treated 
with laser photocoagulation, but the retinal findings remained unchanged. Thirteen months postoperatively, subretinal and intraretinal fluids were observed at the macula, and bestcorrected visual acuity was 0.09 OS.

\section{Case report 2}

A 14-year-old female with left optic disc pit-associated maculopathy and best-corrected visual acuity of 0.04 OS underwent a 20 -gauge pars plana vitrectomy. Triamcinolone acetonide was used intraoperatively to confirm an attached posterior hyaloid membrane. After complete separation of the posterior hyaloid membrane, fluid-air exchange was performed, followed by gas tamponade with sulfur hexafluoride and postoperative facedown positioning for approximately one week. Thirty-six months postoperatively, the retina was attached and best-corrected visual acuity improved to 0.8 OS.

\section{Case report 3}

A 34-year-old female with left optic disc pit-associated maculopathy and best-corrected visual acuity of 0.04 OS (Figure 1A and B) underwent a 23-gauge pars plana vitrectomy. Triamcinolone acetonide was used intraoperatively to confirm an attached posterior hyaloid membrane. After complete separation of the posterior hyaloid membrane, a macular hole was noted. Fluid-air exchange was performed, followed by gas tamponade with sulfur hexafluoride and postoperative facedown positioning for approximately one week. Two months after the vitrectomy, optical coherence tomography revealed a decrease in central retinal thickness and resolution of cystic spaces, and best-corrected visual acuity improved to $0.3 \mathrm{OS}$; however, the macular hole remained open (Figure 1C). A second pars plana vitrectomy procedure with internal limiting membrane peeling and gas tamponade with sulfur hexafluoride successfully closed the macular hole (Figure 1D). Seven months after the first vitrectomy (5 months after the second vitrectomy), the retina was attached and best-corrected visual acuity improved to $1.0 \mathrm{OS}$.

\section{Case report 4}

A 74-year-old male with right optic disc pit-associated maculopathy and best-corrected visual acuity of $0.7 \mathrm{OD}$ underwent a 23-gauge pars plana vitrectomy (Figure 2A and B). Preoperative slit-lamp examination showed a mobile prepapillary glial ring in the right eye. Preoperative assessment of PVD was confirmed intraoperatively by observation using triamcinolone acetonide. Fluid-air exchange
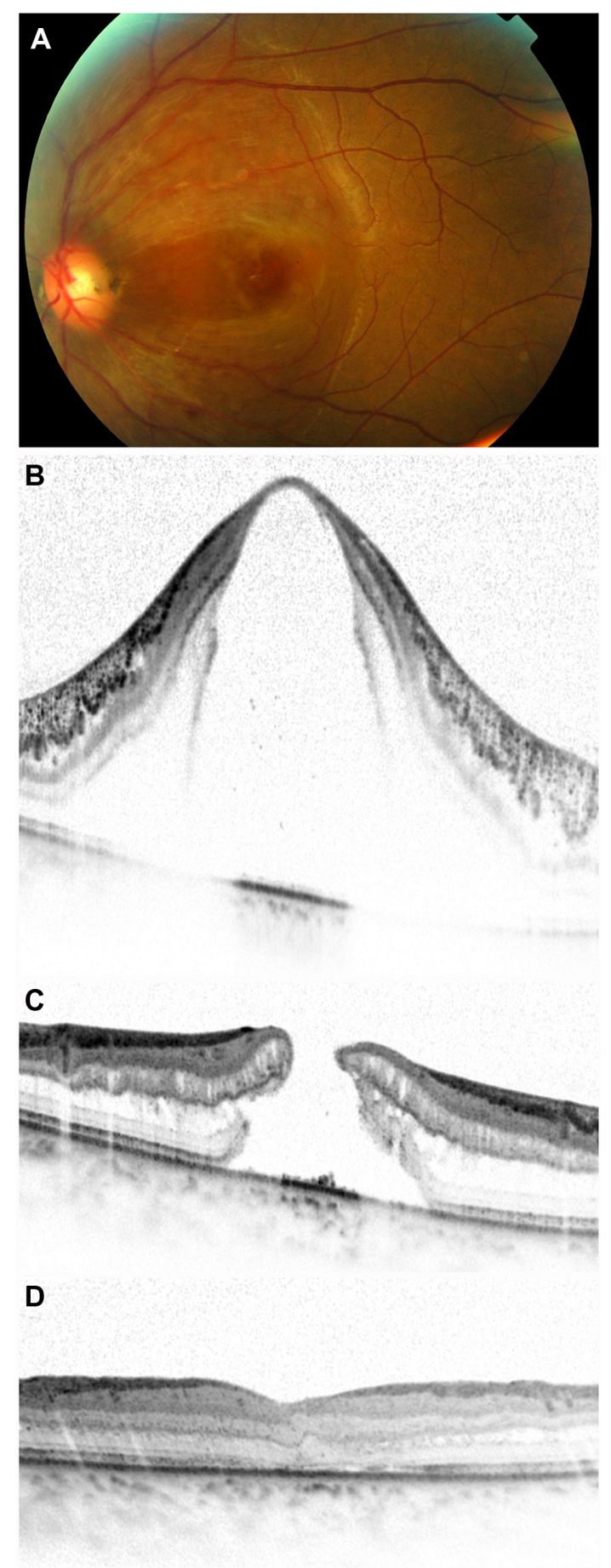

Figure I Case 3. Preoperative fundus photograph showing a temporally located optic disc pit with associated maculopathy (A). Spectral-domain optical coherent tomography (Spectralis, Heidelberg Engineering, Heidelberg, Germany) images through the macula obtained before (B), 2 months after (C), and 3 months after (D) first vitrectomy.

was performed, followed by gas tamponade with sulfur hexafluoride and postoperative facedown positioning for approximately one week. Thirteen months postoperatively, intraretinal fluid was observed at the macula (Figure 2C), and best-corrected visual acuity was $0.5 \mathrm{OD}$. 

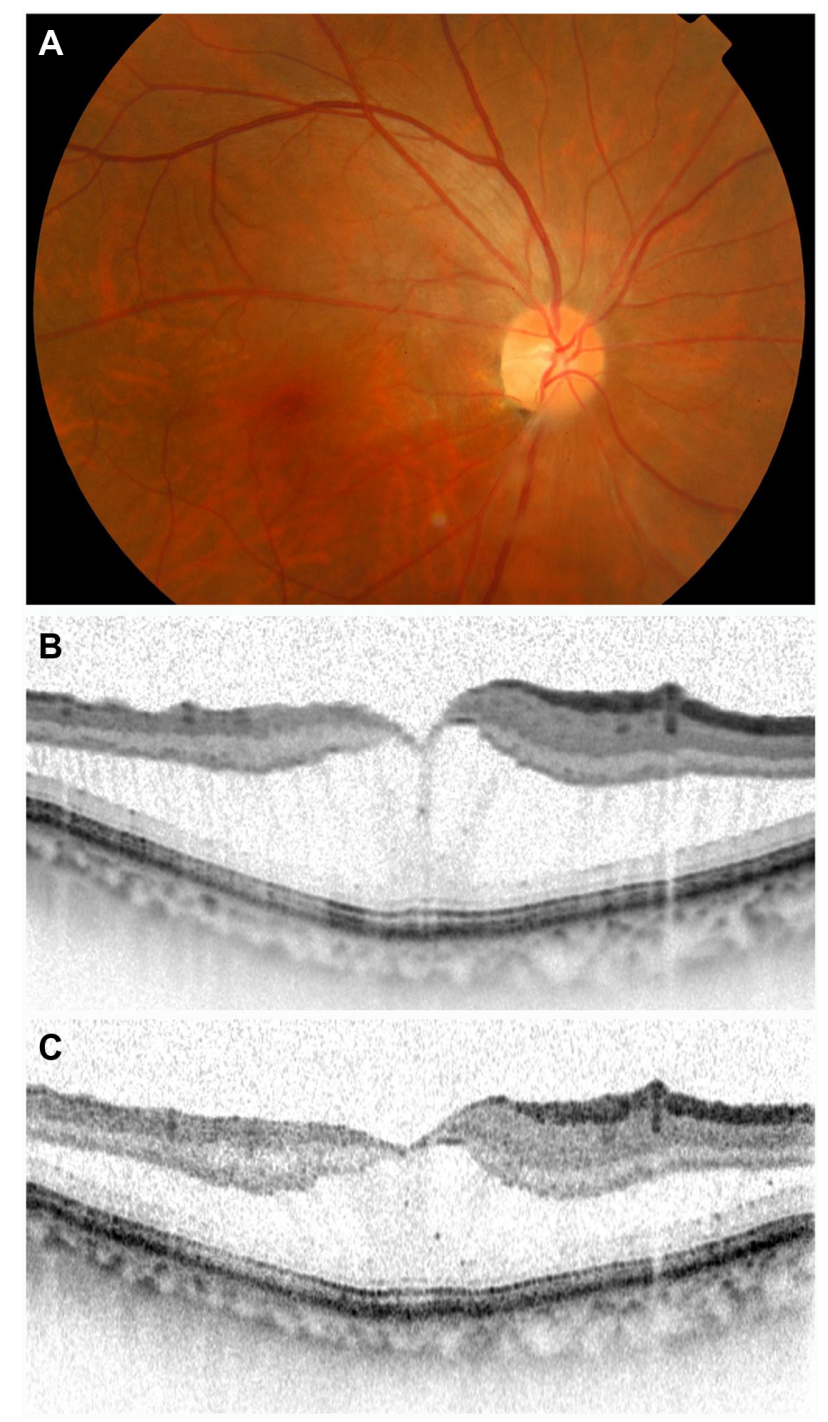

Figure 2 Case 4. Preoperative fundus photograph showing an inferotemporally located optic disc pit with associated maculopathy (A). Spectral-domain optical coherent tomography images through the macula obtained before $(\mathbf{B})$ and I 3 months after (C) the vitrectomy.

\section{Discussion}

Optic disc pit-associated maculopathy may occur at any age but occurs most frequently in early adulthood, and the large majority of eyes with optic disc pit-associated maculopathy are reported to have no PVD. ${ }^{1-3}$ Recent studies have suggested that pars plana vitrectomy with surgical induction of PVD and gas tamponade, with or without internal limiting membrane peeling, is effective for the treatment of optic disc pit-associated maculopathy. ${ }^{4-11}$ Moreover, Hirakata et al reported that induction of PVD without gas tamponade seems to be as effective as doing the same with gas tamponade. ${ }^{12}$ However, there are also cases in which pars plana vitrectomy appears to be ineffective for the treatment of optic disc pitassociated maculopathy. ${ }^{13}$ In addition, there is no available literature that specifies the efficacy of pars plana vitrectomy in patients who already had a PVD at the time of surgery. Brown et al reported that 17 of 21 eyes with optic disc pitassociated maculopathy were noted to have either a partial or a complete PVD, and the age range of those with retinal detachment and PVD was 15-67 years. ${ }^{14}$

In our clinical case series (Table 1), two of four eyes were confirmed to have an attached posterior hyaloid membrane, which was subsequently removed during surgery. Following vitrectomy, these two eyes experienced an improvement in visual acuity with complete retinal attachment of the macula. On the other hand, the other two eyes, which already had a PVD at the time of surgery, showed a decrease in best-corrected visual acuity with persistent maculopathy postoperatively. Sobol et al reported that 10 of 12 untreated patients who did not have spontaneous resolution experienced loss of visual acuity to 20/200 or worse, and anatomic resolution of the serous maculopathy would therefore appear to be a worthwhile goal. ${ }^{15}$

Given that pars plana vitrectomy for optic disc pitassociated maculopathy was effective in two eyes without preoperative PVD but not in two eyes with preoperative PVD, we postulate that pars plana vitrectomy allows reattachment of the macula by releasing preexisting vitreous traction. Therefore, the preoperative condition of the posterior hyaloid membrane seems to be an important factor in determining whether pars plana vitrectomy will provide anatomic flattening of the serous maculopathy and improve best-corrected visual acuity.

In eyes with preoperative PVD, the optic disc pitassociated maculopathy may have derived from a source independent of vitreous traction, such as cerebrospinal fluid or vascular leakage. Another possibility is that the optic disc pit-associated maculopathy with preoperative PVD may have already reached an irreversible phase such that induction of PVD alone is insufficient to correct the condition.

The presence of an intact inner/outer segment junction on preoperative optical coherent tomography images was found to be an important predictor of better visual recovery after epiretinal membrane surgery. ${ }^{16}$ However, our clinical case series (Table 1) suggests that preoperative features of the inner/outer segment junction does not correlate well with improvement of postoperative best-corrected visual acuity in patients with optic disc pit-associated maculopathy.

Given the rarity of optic disc pit-associated maculopathy, the limitations of our study include the retrospective nature of the analysis, the small number of cases, and the unbalanced distribution of patient age. Additional studies involving 
Table I Clinical characteristics of patients with optic disc pit-associated maculopathy

\begin{tabular}{|c|c|c|c|c|c|c|c|c|c|c|c|}
\hline \multirow[t]{2}{*}{ Case } & \multirow{2}{*}{$\begin{array}{l}\text { Age } \\
\text { (years) }\end{array}$} & \multirow[t]{2}{*}{ Gender } & \multirow[t]{2}{*}{ Eye } & \multicolumn{4}{|c|}{ Preoperative } & \multicolumn{3}{|l|}{ Final } & \multirow{2}{*}{$\begin{array}{l}\text { Follow-up } \\
\text { (months) }\end{array}$} \\
\hline & & & & BCVA & PVD & Macula & IS/OS & BCVA & Macula & IS/OS & \\
\hline I & 50 & Male & OS & 0.2 & Present & SRF, IRF & Disrupted & 0.09 & SRF, IRF & Disrupted & 13 \\
\hline 2 & 14 & Female & OS & 0.04 & Absent & SRF, IRF & Disrupted & 0.8 & Attached & Recovered & 36 \\
\hline 3 & 34 & Female & OS & 0.04 & Absent & SRF, IRF & Disrupted & 1.0 & Attached & Recovered & 7 \\
\hline 4 & 74 & Male & OD & 0.7 & Present & IRF & Intact & 0.5 & IRF & Intact & 13 \\
\hline
\end{tabular}

Abbreviations: BCVA, best-corrected visual acuity; IRF, intraretinal fluid; IS/OS, inner/outer segment junction; OD, right eye; OS, left eye; PVD, posterior vitreous detachment; SRF, subretinal fluid.

larger, age-matched groups of patients are needed to confirm our findings.

\section{Conclusion}

Pars plana vitrectomy for optic disc pit-associated maculopathy was beneficial for improving best-corrected visual acuity in two eyes without preoperative PVD but not in two eyes with preoperative PVD. Although neither prospective nor age-matched, our clinical case series suggests that the preoperative assessment of posterior hyaloid membrane is clinically important in predicting the surgical outcome of optic disc pit-associated maculopathy.

\section{Acknowledgment}

This study was supported in part by a Japan Society for the Promotion of Science Grant-in-Aid for Scientific Research (22890230).

\section{Disclosure}

The author reports no conflicts of interest in this work.

\section{References}

1. Gordon R, Chatfield RK. Pits in the optic disc associated with macular degeneration. Br J Ophthalmol. 1969;53:481-489.

2. Bonnet M. Serous macular detachment associated with optic nerve pits. Graefes Arch Clin Exp Ophthalmol. 1991;229:526-532.

3. Postel EA, Pulido JS, McNamara JA, Johnson MW. The etiology and treatment of macular detachment associated with optic nerve pits and related anomalies. Trans Am Ophthalmol Soc. 1998;96:73-88.

4. Georgalas I, Ladas I, Georgopoulos G, Petrou P. Optic disc pit: a review. Graefes Arch Clin Exp Ophthalmol. 2011;249:1113-1122.
5. Hirakata A, Okada AA, Hida T. Long-term results of vitrectomy without laser treatment for macular detachment associated with an optic disc pit. Ophthalmology. 2005;112:1430-1435.

6. Poulson AV, Snead DR, Jacobs PM, Ahmad N, Snead MP. Intraocular surgery for optic nerve disorders. Eye. 2004;18:1056-1065.

7. Todokoro D, Kishi S. Reattachment of retina and retinoschisis in pitmacular syndrome by surgically-induced vitreous detachment and gas tamponade. Ophthalmic Surg Lasers. 2000;31:233-235.

8. Konno S, Akiba J, Sato E, Kuriyama S, Yoshida A. OCT in successful surgery of retinal detachment associated with optic nerve head pit. Ophthalmic Surg Lasers. 2000;31:236-239.

9. Ishikawa K, Terasaki H, Mori M, Sugita K, Miyake Y. Optical coherence tomography before and after vitrectomy with internal limiting membrane removal in a child with optic disc pit maculopathy. Jpn $J$ Ophthalmol. 2005;49:411-413.

10. Georgalas I, Petrou P, Koutsandrea C, Papaconstadinou D, Ladas I, Gotzaridis E. Optic disc pit maculopathy treated with vitrectomy, internal limiting membrane peeling, and gas tamponade: a report of two cases. Eur J Ophthalmol. 2009;19:324-326.

11. Shukla D, Kalliath J, Tandon M, Vijayakumar B. Vitrectomy for optic disk pit with macular schisis and outer retinal dehiscence. Retina. 2012;32:1337-1342.

12. Hirakata A, Inoue M, Hiraoka T, McCuen BW. Vitrectomy without laser treatment or gas tamponade for macular detachment associated with an optic disc pit. Ophthalmology. 2012;119:810-818.

13. Imamura Y, Zweifel SA, Fujiwara T, Freund KB, Spaide RF. High-resolution optical coherence tomography findings in optic pit maculopathy. Retina. 2010;30:1104-1112.

14. Brown GC, Shields JA, Goldberg RE. Congenital pits of the optic nerve head. II. Clinical studies in humans. Ophthalmology. 1980;87:51-65.

15. Sobol WM, Blodi CF, Folk JC, Weingeist TA. Long-term visual outcome in patients with optic nerve pit and serous retinal detachment of the macula. Ophthalmology. 1990;97:1539-1542.

16. Inoue $\mathrm{M}, \mathrm{Morita} \mathrm{S}$, Watanabe $\mathrm{Y}$, et al. Inner segment/outer segment junction assessed by spectral-domain optical coherence tomography in patients with idiopathic epiretinal membrane. Am J Ophthalmol. 2010;150: 834-839.
Clinical Ophthalmology

\section{Publish your work in this journal}

Clinical Ophthalmology is an international, peer-reviewed journal covering all subspecialties within ophthalmology. Key topics include: Optometry; Visual science; Pharmacology and drug therapy in eye diseases; Basic Sciences; Primary and Secondary eye care; Patient Safety and Quality of Care Improvements. This journal is indexed on Submit your manuscript here: http://www.dovepress.com/clinical-ophthalmology-journal

\section{Dovepress}

PubMed Central and CAS, and is the official journal of The Society of Clinical Ophthalmology (SCO). The manuscript management system is completely online and includes a very quick and fair peer-review system, which is all easy to use. Visit http://www.dovepress.com/ testimonials.php to read real quotes from published authors. 